\title{
Congress Destination Attractiveness: The Case of Supply-Side of Business Tourism in Slovenia
}

\author{
Marijana Sikošek \\ University of Primorska, Faculty of Tourism Studies - Turistica, Slovenia \\ marijana.sikosek@fts.upr.si
}

The purpose of the article is to research which attractiveness attributes of a congress destination are those that are important for visiting the congress destination and association meeting, namely from the point of view of the supply-side of business tourism, meaning meeting planners (buyers), suppliers, intermediaries and special agencies. The article redefines the dimensions of visiting a congress destination and the research concept of the supply-side of business tourism. On this basis, we developed a new multidimensional construct (model) of congress destination visit, which takes into consideration three aspects: the destination, venue and business event aspects as the foundation of the supply-side of congress tourism. Based on previous research, we developed a model of attractiveness attributes for each individual aspect which contributes to the visiting of the congress destination. The aim of the research is to contribute to a more comprehensive understanding of the supply-side of congress tourism in a multidimensional analysis of attractiveness attributes of a congress destination which constitute important factors for visiting.

Keywords: congress destination attractiveness, business tourism, conference attributes, congress destination attributes, venue attributes, congress destination visit

(cc) BY-SA https://doi.org/10.26493/2335-4194.13.81-95

\section{Theoretical Background}

In the last decades, there has been an exponential growth in the number of events, which also applies to business events and congress tourism in general (Getz \& Page, 2016). According to the ICCA (see http://www .iccaworld.com), the period between 1963 and 2017 shows a considerable growth, both in terms of international association meetings as well as the number of attendees. With the advent of the economic crisis over ten years ago, a decrease in the number of meetings was recorded as well, which, however, has been on the rise again in the last few years (The Global Association of the Exhibition Industry, 2016).

It was the growth in the volume of business meet- ings that prompted researchers to explore both the reasons and the attributes of attractiveness of a congress destination. This is the central space where a business meeting (conference) takes place and where suppliers, organisers and attendees meet. There are different definitions in literature in the conceptualisation of the congress destination (Oppermann, 1996a, 1996b; Oppermann \& Chon, 1997; Rogers, 1998; Crouch \& Ritchie, 1998; Swarbrooke \& Horner, 2001; Petersen, 2005; Davidson \& Rogers, 2006; Rogers, 2008), and these are often not uniform, especially when defining its dimensions and spatial framework. A review of literature shows that a congress destination can be defined as a spatial, substantive and service entity. Clas- 
sifying congress destinations based on the substantive principle means classifying them according to the different types of business meetings (Swarbrooke \& Horner, 2001), such as congress destination, incentive destination, or exhibition destination (Lu \& Cai, 2009).

A narrower understanding of a congress destination as a spatial entity means understanding a destination as a location where a congress will take place (Rogers, 1998; Baloglu \& Love, 2005; Millar \& Kerr, 2009; Shin, 2009; Del Chiappa, 2012). A destination is defined in a broader sense by Swarbrooke and Horner (2001), who understand it as the central location or place of business travel with the purpose to attend a business meeting. At the same time, they point out the need to distinguish between the terms 'congress destination' and 'congress venue,' as a destination is to be understood as an area, whereas a venue is to be seen as an independent unit of said area, meaning a 'destination' is considered to be a broader term compared to a 'venue.' Nevertheless, we found quite a few examples in literature where a congress venue is interpreted as a destination (Robinson \& Callan, 2005; Millar \& Kerr, 2009; Shin, 2009; Del Chiappa, 2012). Oral and Whitfield (2010) use the terms 'macro-destination,' which includes the attributes of a broader destination, and 'micro-destination,' including venue, accommodation and restaurant services.

To view the concept of a congress destination in a more complex manner, the destination should also be understood as a space that provides suitable services and amenities for a business meeting. Literature thus most often mentions the concept of a congress destination as a space that acts as a host destination for the organisation of congresses (Oppermann \& Chon, 1997; Rogers, 1998; Swarbrooke \& Horner, 2001; Rogers, 2008). However, according to Davidson and Rogers (2006), and Rogers (2008), a destination is also referred to as a combination of different attributes, factors, attractions, services and stakeholders in a specific space or location.

Fundamental to the existence of a congress destination and congress tourism is the content of its services, meaning congress-related products. The congress programme can be understood as the essence of a business event, as content is what defines it. The latter is also the basic motive for the travel of the business tourist, and the basic motive of the meeting planner (organiser) for the organisation of the conference. Zhang et al. (2007) view the core congress product in a similar way, arguing that the essential product of a conference is its programme.

The understanding of the attendance of a conference and destination is often associated with the understanding of the motives and factors contributing to the decision to attend a conference and thus to visit the destination. In congress tourism, attendance as a quantitative category is very often mentioned in relation to the performance of either the meeting planner (organiser), supplier or the destination. The criteria we see is either the number of attendees or, more often, the number of conferences held over a given period (Crouch \& Ritchie, 1998; Nelson \& Rys, 2000; Fawzy \& Samra, 2008; Elston \& Draper, 2012). In terms of content, attendance is a category that means attending a conference (Crouch \& Ritchie, 1998; Rittichainuwat et al., 2001; Comas \& Moscardo, 2005; Petersen, 2005; Robinson \& Callan, 2005; Severt et al., 2009; Lee \& Back, 2010; Tanford et al., 2012; Ramirez et al., 2013), meaning that an attendee is understood as a person who attends the conference programme. Oppermann and Chon (1997) already mentioned different segments of meeting participants and the related different activity of attending or visiting both the conference and the destination, so the attendance category can be understood in two manners. In a narrow sense, the attendance of a conference is understood as the attendance of a conference participant in the substantive program of the conference taking place in a specific venue; more broadly, it also means visiting a congress destination. As authors (Oppermann \& Chon, 1997; Upchurch et al., 2000; Rittichainuwat et al., 2001; Tanford et al., 2012; Oral \& Whitfield, 2010; Del Chiappa, 2012) often point out destination attractiveness attributes as important factors as well, attendance is understood in its broader meaning.

As Getz and Page (2016) point out, researchers pay considerable attention to questions about reasons and motives for attending (visiting), loyalty, or attractiveness attributes of attraction of a congress destination. 
We find that the authors were looking for models and approaches that would provide the most comprehensive answer and solutions that would give the meeting planners and suppliers at the destination a competitive advantage and have a positive impact on the visit and experience of all destination stakeholders. DiPietro et al. (2008) believe that the primary goal of meeting planners is to find a destination that meets the goals of the planned congress, as this is what the number of attendees will depend on. Breiter and Milman (2006, p. 1370), however, are convinced that 'the destination where the congress will take place is important for a participant in deciding whether or not to attend' Whitfield et al. (2014) found that research usually includes three most important directions, namely, research of the process of choosing a location or venue (Crouch \& Louviere, 2004; Robinson \& Callan, 2005; Fawzy \& Samra, 2008); research of the attractions of the destination or venue for the participant (Breiter \& Milman, 2006; Whitfield \& Weber, 2011; Weber \& Chon, 2002), or research of the congress destination image (Oppermann, 1996b; Baloglu \& Love, 2005). Considerable research has also been dedicated to satisfaction and loyalty to the destination (Choi, 2005; Lu \& Cai, 2009; Lee \& Back, 2010; Tanford et al., 2012).

The analysis of the selected papers of research on destination attractiveness attributes from the point of view of the meeting planner shows that they are most often associated with the attributes of accommodation and congress venue capacity, as they appear in all research. Hotel and venue services are often considered simultaneously, confirming the professional practice that most congresses take place in hotels (Rogers, 2008; Robinson \& Callan, 2005). In terms of frequency, following immediately behind is the cost/expense aspect, especially the costs within the destination, the cost of the venue and the accommodation. Attributes related to the attractiveness of congress halls ranked third in terms of frequency, with the capacity and services provided being the leading attributes. Destination attributes are very often associated with the accessibility of the destination itself; only four of the studies analysed do not mention accessibility as such (Edelstein \& Benini, 1994; Robinson \& Callan, 2002). The accessibility attribute is not always understood in terms of physical accessibility, but also as an attribute of destination affordability (Nelson \& Rys, 2000). Other less frequently mentioned attributes of destination attractiveness are out-of-congress facilities, the image of the destination, security, professional congress staff, local hospitality, attractions, local support and others.

On the other hand, we were also interested in establishing how the attributes of destination attractiveness were evaluated from the point of view of the attendee, that is, the one who was already perceived by Var et al. (1985) as an important factor when deciding to attend a conference and thus visit the destination. In an analysis of selected studies, we established that the most important attribute of attractiveness or motive for attending is the destination or conference location; Mair and Thompson (2009) are in fact convinced this is one of the most important attributes, with accessibility and attractiveness being at the forefront. It is closely related to the dimensions of accessibility and attraction of a destination, which are, as a redefinition of the Oppermann-Chon model (1997), supported by Zhang et al. (2007). The dimension of accessibility is often expressed by the distance to the host destination, the travel time, and transport connections, as well as the formalities that need to be arranged to enter the country, whereas the dimension of attraction is expressed with the image of the destination, its climate, the hospitality of the locals, and the culinary and leisure selection at the destination, as well as the past experience of an individual. According to Jago and Deery (2005), the attractiveness of a destination is also an important element for meeting planners, who, as a result of its attractiveness, attract more visitors at the conference and thus higher revenue. In terms of content, the destination is also associated with its image, environment and climate and, ultimately, its reputation (Whitfield et al., 2014). As emphasised by Rittichainuwat et al. (2001) and Whitfield et al. (2014), the opportunity to visit a destination is not to be neglected as an additional form of motivation to visit. One of the most common attributes is the attractiveness of the content or the conference program. This is closely linked to the attributes of networking and professional development, career opportunities, vali- 
dation and reputation in the profession, and personal advancement (Rittichainuwat et al., 2001; Lee \& Back, 2008; Yoo \& Chon, 2008; Mair \& Thompson, 2009; Shin, 2009; Whitfield et al., 2014).

Another important attractiveness attribute is the cost of attending a conference at a destination, in particular the amount of registration fees, transportation and accommodation (authors). Important attributes that attendees think of are also those that may lead them not to attend the conference, and were referred to as 'intervening opportunities' by Oppermann and Chon (1997, p. 186). These may be more attractive conferences with more prominent key-note speakers, or those taking place at the same time, as noted by Mair and Thompson (2009). Authors also classify in this same group the overlaps with the holidays of an individual (Oppermann \& Chon, 1997; Zhang et al., 2007; Mair \& Thompson, 2009), whereas some also include the health of the individual (Rittichainuwat et al., 2001; Mair \& Thompson, 2009) or overlaps with other conferences in this category (Mair \& Thompson, 2009), especially as it is often pointed out that participants are 'time-poor' (Jago \& Deery, 2005; Yoo \& Chon, 2008).

An overview of research shows that the content representation of individual attractiveness attributes is very diverse and structured differently. We found that, in terms of meaning, they could be split into multiple dimensions, such as destination, conference/content, and venue attributes. Whitfield et al. (2014) also noted that attractiveness attributes could be divided into destination attributes, event attributes, and facilities attributes.

We found that in the research done so far, the biggest gap can be seen in the approach when considering the attributes of destination attractiveness. Firstly, there is no approach that would simultaneously check the willingness to visit a congress destination through the various groups of attractiveness attributes that are typical of a congress destination. Secondly, there is no approach that would verify the attributes of attractiveness based on the opinions of the supply-side of business tourism as a whole, as it is composed of meeting planners (buyers), suppliers, intermediaries, and special agencies as defined by Swarbrooke and Horner (2001), although Var et al. (1985)

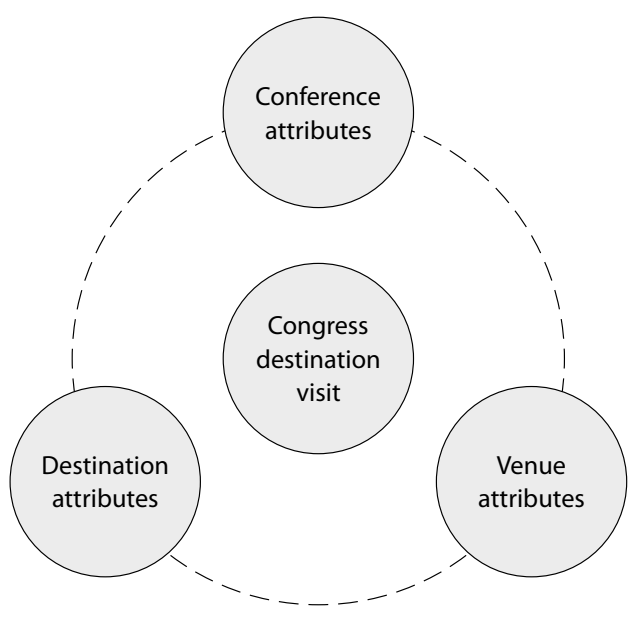

Figure 1 Multi-Dimensional Construct of Congress Destination Visit

already pointed out that the common goal of both the associations (organisers) and the host destination offering congress services, is maximizing the number of conference attendees. Our way of thinking is supported by the findings of some authors (Oppermann \& Chon, 1997; Jago \& Deery, 2005; Yoo in Chon, 2010; Whitfield et al., 2014), who state that the factors and attributes of a congress destination should be evaluated from different perspectives.

The main purpose of business travel is precisely to travel to a destination for business interests, where business travellers meet as part of the event by attending a congress (event) held at a congress venue at the congress destination. On this basis, we assume that the visit of the congress destination is the result of a combination of three factors - destination, venue, and the conference (event) - and introduce a multidimensional congress destination visit construct consisting of the group of destination attractiveness attributes, the group of conference attractiveness attributes, and the group of venue attractiveness attributes.

\section{Methodology}

The purpose of the research is to find those factors of attractiveness of a congress destination that service providers and organisers of business meetings consider to be important in choosing a congress desti- 
nation. We designed a multidimensional construct of congress destination attractiveness as a starting point for empirical research. The necessity for designing a multidimensional construct was also based on the opinion of the authors of Whitfield et al. (2014), who propose to address the attractiveness attributes on several levels.

Based on the substantive analysis of the literature we incorporated different aspects in each group of attractiveness attributes within the construct, and identified them with individual elements. The group of destination attributes thus included destination accessibility, attractiveness, services and conditions at the destination, as well as the reputation of the destination. The ones we classified as venue attributes include venue services, accommodation, type of venue, venue accessibility, congress hall features, and venue reputation. The elements of the group of attractiveness attributes include business opportunities, networking, intervening opportunities, the content of the conference and its reputation.

The multidimensionality of the construct of congress destination attractiveness was tested using Exploratory Factor Analysis (EFA). In general, factor analysis is used to analyse phenomena that cannot be directly measured. The purpose of exploratory factor analysis was to identify relevant factors by individual attractiveness groups. Given the relatively large number of researched attributes, dictated by the complexity of the case under study, factor analysis was performed separately for individual attribute groups.

\section{Research Sample and Instrument}

The research sample consisted of organisations on the supply-side of business tourism in Slovenia. Their number can roughly be estimated based on the results of the Congress Capacity Study of Slovenia (Sikošek et al., 2014). Congress venue suppliers account for the largest number, estimated at 208 in the research; there are far fewer other supply-side organisations, such as professional congress organisers (PCOS), destination management companies (DMCS), incentive travel agencies, convention visitors bureaus (CVBs), carriers, caterers, and event agencies. It is difficult to estimate the volume of meeting planners, as it is usually a trade secret of suppliers. Robinson and Callan (2002) encountered the same dilemma of determining the population of meeting planners, where they reported on the absence of a central client list. The sample of meeting planners includes those who organised association meetings at least in the last year, or are suppliers of congress services in the territory of Slovenia. We obtained their addresses based on our own research; part of the meeting planners' addresses were obtained with the help of PCOS, CVBS and DMCs. The questionnaire was sent to 1558 addresses.

The introductory part of the questionnaire was aimed at obtaining data on the profile of the respondent with closed-ended questions. The central part was substantive in nature, and was divided into three sets of statements, separated into: destination attributes, conference attributes, and venue attributes.

Surveys were conducted over a three-week period using the online survey technique using the $1 \mathrm{KA}$ web application. After three weeks of surveying, after having exhausted the willingness of respondents to participate, we received 171 returned questionnaires, which represents a $10.8 \%$ response rate. Out of 171 questionnaires received, 49 were excluded as ineligible for further analysis due to the excessive number of missing answers. Thus, 122 survey questionnaires were included in the analysis. The data were analysed using SPSS version 22.

\section{Results}

\section{Sample Profile}

Out of the 122 respondents, $75 \%$ were women, and 25\% were men. Their age structure indicates that most of them are in their work intensive period: $35 \%$ are between 31 and 40 years old, $27 \%$ are between 41 and 50 , $26 \%$ of people in the sample are over 51, while at least $11 \%$ are in the $18-30$ age group. Nearly half $(46 \%)$ of respondents have a college or university degree, followed by those with a postgraduate degree (18\%), and only $2 \%$ have a high school degree, and no one has only a primary school education.

The results also show that the respondents have extensive work experience in the organisation where they are currently employed: the largest proportion of respondents have more than ten years of experience, 
Table 1 Working Time (Period of Employment) of Respondents in the Current Organisation

\begin{tabular}{lrr}
\hline Period of employment (in years) & $f$ & $\%$ \\
\hline No answer & 12 & 9.8 \\
Up to 1 year & 5 & 4.1 \\
More than 1 year up to 3 years & 7 & 5.7 \\
More than 3 years up to 5 years & 18 & 14.8 \\
More than 5 years up to 10 years & 27 & 22.1 \\
More than 10 years & 53 & 43.4 \\
\hline Total & 122 & 100.0 \\
\hline
\end{tabular}

Table 2 Current Position of the Respondents in the Working Organisation

\begin{tabular}{lrr}
\hline Job position & $f$ & $\%$ \\
\hline Middle management position & 27 & 22.1 \\
Upper/high management position & 20 & 16.4 \\
Researcher, professor, teacher & 19 & 15.6 \\
Congress management & 17 & 13.9 \\
Marketing, sales & 15 & 12.3 \\
Other & 11 & 9.0 \\
No answer & 13 & 10.7 \\
\hline Total & 122 & 100.0 \\
\hline
\end{tabular}

and almost a quarter have between five and ten years of work experience in the meetings industry. Other researchers (Baloglu \& Love, 2005) provided similar results.

Most of the supply-side organisations surveyed (22.1\%) hold a leading position, such as area manager. Those in managerial positions, such as directors, account for $16.4 \%$. Researchers, professors and teachers account for $15.6 \%$ (Table 1). There are $13.9 \%$ of employees in congress management, such as organisation, administration, technical service, etc., while a slightly lower percentage is employed in marketing and sales $(12.3 \%)$. For 13 of the service providers, we were not able to obtain data on their workplaces.

In identifying the specifics of the sample, we were also interested in the type of supplier. Respondents had the possibility to answer several questions at once, as practice shows that each supplier could perform several activities simultaneously (e.g. venue and PCo).
Table 3 Type of Supply-Side Organisation

\begin{tabular}{lrr}
\hline Type & $f$ & $\%$ \\
\hline Meeting planner ('buyer') & 42 & 36.2 \\
Science/research institution & 31 & 26.7 \\
Venue & 30 & 25.9 \\
CVB/DMO & 11 & 9.5 \\
PCO & 9 & 7.8 \\
DMC, incentive, teambuilding services & 8 & 6.9 \\
Other & 16 & 13.8 \\
\hline
\end{tabular}

On average, they stated 1.3. The structure of supplyside organisations indicates that a considerable proportion of survey participants were meeting planners, as in $36.2 \%$ of cases, the respondents stated that they were either clients or organisers of the meetings (Table 3). More than a quarter $(26.7 \%)$ of respondents work in a scientific research institution, and these are often meeting planners. Slightly fewer $(25.9 \%)$ are venue suppliers, who, however, stated that they were representatives of a hotel with conference facilities $(n=14)$, a congress hotel $(n=5)$, a congress or exhibition centre $(n=4)$, or a special venue $(n=1)$.

Further on, we were also interested in how many conferences are organised by the respondents. Half of them stated that their organisation organises up to five conferences annually, and just under a fifth (18.0\%) between 6 to 10 conferences. More than a tenth of the participating organisations (11.5\%) organise from 11 to 30 conferences, $5.7 \%$ organise from 31 to 50 , and a tenth (10.7\%) of them organise more than 50 . For $4.1 \%$ of respondents we were unable to obtain this information.

\section{Factor Analysis Results}

Considering that a similar multidimensional attribute model for the attractiveness of the congress destination with three groups of factors has not yet been constructed, it was necessary to form a set of statements related to each group of attributes for the purpose of this research. We thus classified the statements into three groups. Due to the complexity of the studied problem, we decided to perform a separate factor analysis for each group. The statements were checked the same way in each group: with a Likert-type scale, 
where the respondents rated agreement with each statement, where a score of 1 meant they 'completely disagree,' a score of 2 meant they 'disagree,' a score of 3 meant they 'partially agree,' a score of 4 meant they 'agree' and a score of 5 meant they 'strongly agree.' We deliberately formed some statements with a negative meaning. In this case, we reversed the rating scale so that the higher value was always associated with a stronger agreement with the importance of the item being evaluated. We marked such elements with (R).

\section{Destination Attractiveness Attributes}

In the final model 13 of the original 19 statements were used. The adequacy of variable inclusion in the final factor model was verified by кмо statistics; its value amounted to 0.74 , which indicates the median suitability of the data (к мо > 0.7) for further factor analysis. The adequacy of the data to obtain the final factor solution is further confirmed by Bartlett's test of sphericity $(p=0.0)$. The eigenvalue diagram showed one more prominent factor and three slightly less prominent ones. The results therefore show that the opinions of the surveyed suppliers regarding the attractiveness attributes of the destination can be explained by four common factors, all of which together account for $53.3 \%$ of the total variance explained, which is an acceptable value. To obtain a clearer structure of the final solution, we carried out a rotation using the varimax method. The final factor solution is shown in Table 4. To achieve better clarity, only those factor loadings that show a significant impact are shown $(<-0.3$ or $>0.3$ ). We added the calculated proportion of the total variance explained to the structure of factor loadings, as well as Cronbach's coefficient of reliability of an individual factor, which ranges between 0.74 and 0.77 in the case of three factors, which is considered very good, whereas for the fourth, 0.83 indicates exemplary reliability.

The results of the factor analysis showed that a total of four factors can determine attractiveness. According to the respondents, these are the factors that are important in choosing a host destination for the organisation of the conference, and thus for attracting potential visitors to the destination. According to the suppliers, the evaluation of the attractiveness of the destination as the place where the conference is organised refers to the reputation of the place, the attractions of the destination, its accessibility and leisure activities available at the destination.

The first factor is the one that explains the largest proportion of the total variance, namely $16.2 \%$. According to the content of individual variables, which stand for the general characteristics of the place where the conference is organised, we named this factor reputation. It is most strongly defined by the destination security variable, followed by the attitude of the locals towards the conference guests and the development of local infrastructure. According to the suppliers, the reputation of the destination is also indicated by the good opinion of the professional public about the destination, which facilitates the decision to organise the conference at the destination itself, and is also a result of a stimulating economic environment.

The second factor was associated with attractions, and it accounts for $12.9 \%$ of the total variance. It is determined by the culinary selection of the destination, the sights at the destination and the favorable climatic conditions.

The third factor, which accounts for $12.2 \%$ of the total variability, is the factor related to the accessibility of the destination, in which case its attractiveness is reduced by a great distance from the original destination, which is usually associated with high transportation costs to the host destination. Last but not least, a destination may be less accessible and thus, according to the service providers, also less attractive due to the time-consuming arrangement of formalities to enter the country.

The fourth factor is associated with leisure activities at the destination, which accounts for $12 \%$ of the total variance. The result is almost somewhat surprising, as organisers have not paid much attention to 'noncongress' activities so far. It is true, however, that such activities are becoming increasingly more attractive for the organisation of the conference at the destination.

\section{Venue Attractiveness Attributes}

The final factor solution retained ten variables out of a total of 22 originally included. The кмо statistic value 
Table 4 Rotated Factor Solution: Destination Attributes

\begin{tabular}{|c|c|c|c|c|}
\hline Item (variable) & (1) & $(2)$ & (3) & (4) \\
\hline When organising a conference, it is better if a destination is considered safe. & 0.71 & & & \\
\hline $\begin{array}{l}\text { It is better to have locals with a positive attitude towards guests (they are hospitable, kind, } \\
\text { fluent in foreign languages) when organising a conference. }\end{array}$ & 0.74 & & & \\
\hline $\begin{array}{l}\text { When organising a conference, it is better if a destination has a well-developed local } \\
\text { infrastructure. }\end{array}$ & 0.67 & & & \\
\hline $\begin{array}{l}\text { If the professional public (journals, online journals, professional associations, social } \\
\text { networks) has a positive opinion about a destination, the decision for organising a } \\
\text { conference is faster, easier. }\end{array}$ & 0.50 & & & \\
\hline It is important that the economic environment of a destination is encouraging. & 0.34 & & & \\
\hline It is important that a destination has a well-developed culinary offer. & & 0.80 & & \\
\hline $\begin{array}{l}\text { When deciding to organise a conference, it is important for a destination to offer tourist sites } \\
\text { and attractions. }\end{array}$ & & 0.72 & & \\
\hline $\begin{array}{l}\text { Favourable climate/weather conditions at a destination facilitate opting for the organisation } \\
\text { of a conference. }\end{array}$ & & 0.51 & & \\
\hline Remoteness of a destination makes it less attractive for organising a conference there. & & & 0.79 & \\
\hline High transport costs make a destination less attractive for organising a conference there. & & & 0.66 & \\
\hline $\begin{array}{l}\text { Time-consuming arrangement of formalities when entering a country (obtaining visas, } \\
\text { procedures at crossing borders) makes a destination less attractive for organising a } \\
\text { conference there. }\end{array}$ & & & 0.60 & \\
\hline $\begin{array}{l}\text { When deciding whether to organise a conference, it is irrelevant whether a destination offers } \\
\text { good possibilities for shopping. }\end{array}$ & & & & 0.86 \\
\hline $\begin{array}{l}\text { When deciding whether to organise a conference, it is irrelevant whether a destination offers } \\
\text { a variety of leisure activities (night clubs, bars, theatres,...). }\end{array}$ & & & & 0.79 \\
\hline Total variance explained (\%) & 16.18 & 12.92 & 12.19 & 12.03 \\
\hline Reliability Coefficient (Cronbach’s alpha) & 0.77 & 0.75 & 0.74 & 0.83 \\
\hline
\end{tabular}

Notes Factors: (1) reputation, (2) attractions, (3) accessibility, (4) leisure activities.

amounts to 0.81 , which means it is estimated as suitable to be included in the model. The adequacy of the data to obtain the final factor solution is further proven by Bartlett's test of sphericity $(p=0.0)$. In estimating the proportion of total variance explained, we found that a total of three factors account for $44.4 \%$ of the total variability in the sample. The final factor solution was formulated by three common factors and is presented in Table 5. To achieve better clarity, only those factor loadings that show a significant impact are shown $(<-0.3$ or $>0.3)$. The calculated proportion of the total variance explained and the Cronbach's alpha were added to the structure of factor loadings for each individual factor. This amounts to 0.70 for the first one, which can be estimated as good reliability, whereas for the other two factors, the value is 0.66 for the second and 0.67 for the third factor, which can be estimated as moderate reliability (Nunally, 1978).

The first factor, which accounts for $18.1 \%$ of the variability in the sample, is the organisation of the venue, which can be associated with the professional work of the staff at the venue, as well as the efficiency of the registration process and the speed of entry or exit from the venue, and last but not least, the adequate arrangement of conference facilities, such as their clear labelling. Ensuring security is also one of the parameters of the organisation of the venue.

The share of the total variance explained for the 
Table 5 Rotated Factor Solution: Venue Attributes

\begin{tabular}{|c|c|c|c|}
\hline Item (variable) & (1) & $(2)$ & (3) \\
\hline It is expected of the staff at the venue to be professional. & 0.79 & & \\
\hline $\begin{array}{l}\text { It is expected that a venue offers a possibility to organise an effective registration process and a fast } \\
\text { entrance to/exit from the venue. }\end{array}$ & 0.78 & & \\
\hline A pleasant atmosphere at a venue is not important. & & & 0.83 \\
\hline $\begin{array}{l}\text { It is not important that a venue offers additional services, for example the possibility to use their } \\
\text { offices, wardrobes, carrying as well as storing of materials and similar. }\end{array}$ & & & 0.57 \\
\hline $\begin{array}{l}\text { When organising a conference, it is important to have an appropriate number of hotel rooms } \\
\text { (rooms for accommodation) with respect to the size of the conference. }\end{array}$ & & 0.64 & \\
\hline It is important that a venue offers good connections for local transport. & & 0.57 & \\
\hline $\begin{array}{l}\text { It is better if accommodation is as close as possible to the conference venue (facilities in which the } \\
\text { conference takes place). }\end{array}$ & & 0.41 & \\
\hline $\begin{array}{l}\text { The size and number of halls have to be appropriate for the size of a conference (the number of } \\
\text { attendees). }\end{array}$ & & 0.42 & \\
\hline $\begin{array}{l}\text { Conference facilities at a venue must be appropriately organised (markings, interior design, toilet } \\
\text { facilities). }\end{array}$ & 0.36 & & \\
\hline Safety at a venue is important. & 0.44 & & \\
\hline Total variance explained (\%) & 18.13 & 13.79 & 12.44 \\
\hline Reliability Coefficient (Cronbach's alpha) & 0.70 & 0.66 & 0.67 \\
\hline
\end{tabular}

Notes Factors: (1) organisation, (2) infrastructure, (3) additional services.

second factor amounts to $13.8 \%$, and is associated with the infrastructural arrangement of the venue. It is defined by variables relating to conference facilities as such on the one hand, and to accommodation on the other. Conference facilities at the venue should have an appropriate ratio between the size and number of halls and the volume of the conference, which undoubtedly facilitates its organisation. The results also show that the infrastructure arrangement of the venue is determined by its distance to local connections. It is not surprising that accommodation can be linked to the venue, as we established both in theory and in practice that the venue and accommodation are often linked together in a meaningful whole. The characteristics of the individual variables that are linked within the factor of infrastructure lead us to think that these are the characteristics of the venue that facilitate the organisation of the conference.

A somewhat smaller proportion of the total variance explained (12.4\%) is associated with the third factor, which is related to additional venue services. It refers to elements that facilitate the organisation of the conference and include those venue services that typically represent the 'invisible' hand of the organisation. In fact, the results show that this refers to a pleasant atmosphere created by the venue and a variable that reflects the technical nature of the organisation, such as the possibility to use an office, changing rooms, and material storage facilities.

\section{Conference Attractiveness Attributes}

After a substantive analysis, we decided to include 12 variables in the final solution. The relevance of inclusion is confirmed by кмо statistics, amounting to 0.793 , and Bartlett's test of sphericity $(p=0.00)$. The assessment of the total variance explained and the eigenvalue of the individual factors showed that the attractiveness of the conference can be explained by four factors, their total variance being $58.2 \%$. The final factor solution after rotation is shown in Table 6. The calculation of the reliability coefficient indicates exemplary reliability in the opportunity factor (o.83), 
whereas the reliability in the reputation and networking factors is very good ( 0.79 and 0.78 respectively). In terms of the content factor, the Cronbach's coefficient in the amount of 0.60 is at the border of moderate reliability.

The factor loadings matrix shows that the first factor is defined by four variables. This is related to conference opportunities and accounts for $18.5 \%$ of variability in the sample. From the organisers' point of view, the opportunity factor should be understood primarily as creating an opportunity for the attendee, and thus fulfilling the basic mission of the conference, which is primarily meant to be a place for business meetings between individuals. From a service provider's perspective, conference opportunities are those that allow for the exchange of experience, the search for new opportunities and contacts, and the acquisition of knowledge, and ultimately an opportunity to meet experts.

The second factor, accounting for $15.2 \%$ of the total variance explained, was the factor associated with the reputation of the conference, which is determined by exactly the same variables as we had anticipated in the design phase of the survey. Reputation is a conference factor that relates to the opinion of the external public. This is the opinion that former attendees and the professional public have of the conference, and positive past experiences of the attendees with the conference, which should contribute to the efforts of suppliers to optimize the organisation of the conference, which can lead to better opportunities in conference selection and attendance.

The third factor, which accounts for $13.2 \%$ of sample variability, is associated with networking. It is linked with opportunities to find new business partners and meet existing ones.

The fourth factor of conference attractiveness is associated with conference content, and accounts for $11.3 \%$ of the variability in the sample. According to the suppliers, the content of the conference is most determined by interesting contributions or content appearing in the conference program, especially if they represent something original in comparison to previous conferences, and by the presence of prominent speakers at the conference.

\section{Findings and Discussion}

Our starting hypothesis is based on the realization that visiting a congress destination is possible due to the existence of attractiveness of the congress destination, which is not a unique construct, but is defined by three groups of attractiveness attributes that arise from the necessity for the existence of three fundamental components of a congress destination: attractiveness of the destination as a place, attractiveness of the venue and attractiveness of the conference. We examined it using the results of exploratory factor analysis by individual groups of attractiveness of a congress destination. The summary of results is shown in Table 7 .

The results show that destination attractiveness is determined by the reputation of the destination, the attractions at the destination, accessibility to the destination and leisure activities at the destination, characterized by 13 variables. Cronbach's coefficient values for these factors express very good or exemplary reliability, as they range between 0.74 and 0.83 , indicating that individual dimensions of destination attractiveness on the service provider's end define the construct appropriately.

According to the results of the analysis, the attractiveness of the venue is linked with the organisation of the venue, the infrastructure and the additional services of the venue, characterised by a total of 10 variables. Considering the values of the reliability coefficient, which ranges from 0.66 to 0.70 , we can summarise that they indicate appropriate result characteristics, meaning the individual dimensions of venue attractiveness on the part of the providers define the measured construct with adequate reliability.

The analysis has shown that conference attractiveness can be defined by a total of four factors, including conference opportunities, the reputation of the conference, networking and the substantive aspect of the conference, which is described by 12 variables. Cronbach's coefficient values for each individual factor range between 0.83 and 0.60 , which indicates a good reliability of the conference attractiveness construct.

The results of exploratory factor analysis are only partially in line with the anticipated theoretical concepts, as it was set out at the beginning of the study that the attractiveness of a destination would consist 
Table 6 Rotated Factor Solution: Conference Attributes

\begin{tabular}{|c|c|c|c|c|}
\hline Item (variable) & (1) & $(2)$ & (3) & (4) \\
\hline Attending a conference is a great opportunity for participants to share experience. & 0.77 & & & \\
\hline $\begin{array}{l}\text { Attending a conference is a great opportunity for seeking new possibilities (markets, } \\
\text { research, companies, cooperations etc.) and contacts. }\end{array}$ & 0.82 & & & \\
\hline Attending a conference is a great opportunity for participants to obtain new knowledge. & 0.66 & & & \\
\hline $\begin{array}{l}\text { Attending a conference is a great opportunity for participants to meet specialists within } \\
\text { their field. }\end{array}$ & 0.49 & & & \\
\hline $\begin{array}{l}\text { It is important for organisation that past participants have a positive opinion about } \\
\text { a conference. }\end{array}$ & & 0.89 & & \\
\hline $\begin{array}{l}\text { It is important for organisation that the professional public (journals, online journals, } \\
\text { professional associations, social networks) has a positive opinion about a conference. }\end{array}$ & & 0.70 & & \\
\hline $\begin{array}{l}\text { If participants have had a good experience with a conference, it is easier for them to decide } \\
\text { to attend it. }\end{array}$ & & 0.52 & & \\
\hline $\begin{array}{l}\text { Attending a conference is a great opportunity for participants to search for new business } \\
\text { partners. }\end{array}$ & & & 0.78 & \\
\hline Attending a conference is a great opportunity for participants to meet business partners. & & & 0.70 & \\
\hline $\begin{array}{l}\text { If the programme, content of a conference represents a novelty with regard to the previous } \\
\text { ones, it is easier/faster to get participants to attend a conference. }\end{array}$ & & & & 0.41 \\
\hline $\begin{array}{l}\text { Interesting contributions (topics) in the programme increase the number of participants } \\
\text { at a conference. }\end{array}$ & & & & 0.70 \\
\hline $\begin{array}{l}\text { The presence of respectable speakers inside a field increases the number of participants } \\
\text { at a conference. }\end{array}$ & & & & 0.58 \\
\hline Total variance explained (\%) & 18.46 & 15.19 & 13.18 & 11.32 \\
\hline Reliability Coefficient (Cronbach's alpha) & 0.83 & 0.79 & 0.78 & 0.60 \\
\hline
\end{tabular}

Notes Factors: (1) opportunity, (2) reputation, (3) networking, (4) content.

of four factors (accessibility, attraction, services and conditions at the destination, reputation of the destination) and five factors of venue attractiveness (accessibility, accommodation, special conference facilities, venue services, accommodation and reputation) and conference attractiveness (business opportunities, networking, intervening opportunities, content and reputation). The research shows that attractiveness factors are shaped differently by individual attractiveness groups. We identified a total of 11 attractiveness dimensions, which are described by a total of 34 elements, and are classified within three groups of attractiveness.

The results of exploratory factor analysis conducted between suppliers and meeting planners undoubtedly indicate the multidimensionality of the congress desti- nation attractiveness construct, defined by destination attractiveness, venue attractiveness, and conference attractiveness, as it turned out that there are a total of 11 dimensions defining it. These are the factors that are important in choosing a congress destination, and thus for attracting potential visitors to the destination. The results also indicate that it would be difficult to separately consider the different items of attractiveness of a congress destination as a factor in visiting, and they should therefore be considered as a comprehensive concept, which, given their multidimensional nature, dictates the simultaneous consideration of all aspects of attractiveness.

Based on the results of the analysis, our thesis can be confirmed, as it turned out that it is possible to determine 11 attractiveness dimensions within individ- 
Table 7 Summary of Results of Exploratory Factor Analysis by Individual Dimensions

\begin{tabular}{|c|c|c|c|}
\hline Category & Item & $\alpha$ & Dimension \\
\hline \multirow[t]{13}{*}{ Destination } & Reputation & 0.77 & Safety of the destination \\
\hline & & & Positive attitude of locals \\
\hline & & & Well-developed local infrastructure \\
\hline & & & A positive opinion of the professional public \\
\hline & & & Encouraging economic environment \\
\hline & Attractions & 0.75 & Well-developed culinary offer \\
\hline & & & Offering tourist sites and attractions \\
\hline & & & Favourable climate/weather conditions \\
\hline & Accessibility & 0.74 & Remoteness of a destination \\
\hline & & & High transport costs \\
\hline & & & Time-consuming arrangement of formalities \\
\hline & Leisure activities & 0.83 & Shopping \\
\hline & & & A variety of leisure activities \\
\hline \multirow[t]{10}{*}{ Venue } & Organisation & 0.70 & Professional venue staff \\
\hline & & & Effective registration process \\
\hline & & & Appropriately organised conference facilities \\
\hline & & & Safety at a venue \\
\hline & Infrastructure & 0.66 & Good connections with local transport \\
\hline & & & Appropriateness of the size and number of halls \\
\hline & & & Vicinity of accommodation \\
\hline & & & Appropriate number of hotel rooms with respect to the size of the conf. \\
\hline & Additional services & 0.67 & Pleasant atmosphere \\
\hline & & & Technical services \\
\hline
\end{tabular}

Continued on the next page

ual congress destination attractiveness groups, which points to the multidimensionality of the congress destination attractiveness construct.

\section{Conclusion}

This paper highlights the multidimensionality of addressing the attractiveness of a congress destination, and points out the need to address it in a comprehensive manner and, ultimately, to interpret the attractiveness of a congress destination as a factor in visiting. It was established that it would be difficult to address individual attributes of attractiveness separately or as an individual entity, but must be viewed in the light of complementarity that gives the items of attrac- tiveness of a congress destination a multidimensional character. The congress destination thus cannot be understood as an individual entity, but as a managerial and organisational compound of different stakeholder groups, which nevertheless want to accomplish a common goal: to hold the conference as its core product, taking into account the attributes of attractiveness that determine both the conference and the venue where it takes place, and considering the attributes of attractiveness of the destination acting as the host location for the conference.

The novelty of the research lies in the changed, more comprehensive view of the attractiveness of the congress destination, which arises from the three con- 
Table 7 Continued from the previous page

\begin{tabular}{llll}
\hline Category & Item & $\alpha$ & Dimension \\
\hline Conference & Opportunities & 0.83 & Sharing experiences \\
& & Seeking new possibilities \\
& & Obtaining new knowledge \\
& & Meeting specialists within the professional field \\
\cline { 2 - 4 } & Reputation & 0.79 & Positive opinion of past participants \\
& & $\begin{array}{l}\text { Positive opinion of professional public } \\
\text { Getworking }\end{array}$ & Good past experiencies \\
\cline { 2 - 4 } & 0.78 & Searching for new business partners \\
& & Meeting existing business partners \\
\cline { 2 - 4 } & Content & Novelty of the content \\
& & Interesting topics \\
& & The presence of respectable speakers \\
\hline
\end{tabular}

ceptual cores or ingredients required in organising the conference: the attractiveness of the destination as a host destination, the attractiveness of the venue as the location where the conference is held, and the attractiveness of the conference as the core product. The research is based on the thinking of Whitfield et al. (2014), who argue that the attractiveness of a congress destination should be considered in the context of three different, but interacting levels. This way, through the construction of a new model and with a newly designed measuring instrument, we tested and confirmed the multidimensionality of addressing the attractiveness of a congress destination.

The restriction of the research is certainly the fact that it was conducted on the territory of Slovenia and on the sample of the association segment, so we were limited to the Slovenian market of association conferences. By expanding the research into a region, such as Southeastern Europe as an important congress destination, we could get a different view of the researched case. Due to the complexity of the model tested, another restriction was that the research does not include members of international congress committees that decide on the destination at transnational level, as highlighted by Crouch et al. (2019).

It is, however, definitely a contribution to addressing the attractiveness of a congress destination with a changed view of the things that make it attractive, which requires the construction of a new model, measuring instrument, and its verification. In addition to designing a new, multidimensional construct of attractiveness of a congress destination, our view of understanding the offer on the congress market as a sample on which we tested the model, has also changed. Based on the model first developed by Oppermann and Chon (1997), which is also supported by the recommendations of UNW TO (United Nations World Tourism Organization, 2016), we also included suppliers as well as meeting planners. These two groups are in fact the ones which organise the conference with the aim of attracting as many attendees as possible, as Var et al. (1985) were among the first to point out.

The research possibilities are presented in the following parts of the paper using a developed measuring instrument on the example of individual congress destinations, and on the example of conference and business meeting types. This would make it possible to also gain insight into the special preferences leading to the choice of a congress destination for different, specific segments of congress participants within the association market that our research was aimed at, and to confront them with the guidelines that organisers and suppliers follow when organising business meetings. In the light of determining the attractiveness of 
a congress destination in a multidimensional model, it would also be reasonable to explore the specifics of smaller destinations.

Finally, the proposed construct of congress destination attractiveness could be applied to other types of events as well, because, as Getz and Page (2016) explain it, business events are one of the specific types of planned events in addition to sport events, festivals and other cultural events, and entertainment events. By appropriately modifying the measuring instrument, the existing construct would thus be tested on other types of events and at different destinations, which would contribute to a broader understanding of the attractiveness of different types of events.

\section{References}

Baloglu, S., \& Love, C. (2005). Association meeting planners' perceptions and intentions for five major us convention cities: The structured and unstructured images. Tourism Management, 26(5), 743-752.

Breiter, D., \& Milman, A. (2006). Attendees' needs and service priorities in a large convention center: Application of the importance-performance theory. Tourism Management, 27(6), 1364-1370.

Choi, J. J. (2005). Factors influencing state association planners' overall satisfaction with a convention experience. Journal of Convention \& Event Tourism, 6(4), 65-8o.

Comas, M., \& Moscardo, G. (2005). Understanding associations and their conference decision-making processes. Journal of Convention \& Event Tourism, 7(3/4), 117-138.

Crouch, G. I., \& Brent Ritchie, J. R. (1998). Convention site selection research: A review, conceptual model, and propositional framework. Journal of Convention \& Exhibition Management, 1(1), 49-69.

Crouch, G. I., \& Louviere, J. J. (2004). The determinants of convention site selection: A logistic choice model from experimental data. Journal of Travel Research, 43(2), 118130.

Crouch, G. I., Del Chiappa, G., \& Perdue, R. R. (2019). International convention tourism. Tourism Management, 71, 530-542.

Davidson, R., \& Rogers, T. (2006). Marketing destinations and venues for conferences, conventions and business events. Routledge.

Del Chiappa, G. (2012). How do meeting organisers choose convention sites based on different types of meetings? An empirical analysis of the Italian meetings industry. Event Management, 16(2), 157-170.
DiPietro, R. B., Breiter, D., Rompf, P., \& Godlewska, M. (2008). An exploratory study of differences among meeting and exhibition planners in their destination selection criteria. Journal of Convention \& Event Tourism, 9(4), 258-276.

Edelstein, L. G., \& Benini, C. (1994). Meeting market report 1994. Meetings \& Conventions, 29(9), 60-62.

Elston, K., \& Draper, J. (2012). A review of meeting planner site selection criteria research. Journal of Convention \& Event Tourism, 13(3), 203-220.

Getz, D., \& Page, S. J. (2016). Progress and prospects for event tourism research. Tourism Management, 52, 593-631.

Jago, L. K., \& Deery, M. (2005). Relationships and factors influencing convention decision-making. Journal of Convention \& Event Tourism, 7(1), 23-41.

Lee, J. S., \& Back, K. J. (2010). Reexamination of attendeebased brand equity. Tourism Management, 31(3), 395401.

Lu, Y., \& Cai, L. A. (2009). Analysis of image and loyalty for exhibitions and host destinations. Scholarworks. http:// scholarworks.umass.edu/refereed/Sessions/Saturday/15/

Mair, J., \& Thompson, K. (2009). The U K association conference attendance decision-making process. Tourism Management, 30(3), 400-409.

Millar, M., \& Kerr, G. M. (2009). Conventions held by associations: A case study of buyers and suppliers in an emerging conference destination. In J. Carlsen, M. Hughes, K. Holmes, \& R. Jones (Eds.), Proceedings of the 18th Annual CAUTHE Conference (pp. 1-20). Curtin University of Technology.

Nelson, R., \& Rys, S. (2000). Convention site selection criteria relevant to secondary convention destinations. Journal of Convention \& Exhibition Management, 2(2-3), 7182.

Oppermann, M. (1996a). Convention cities: Images and changing fortunes. Journal of Tourism Studies, 7(1), 1019.

Oppermann, M. (1996b). Convention destination images: Analysis of association meeting planners' perceptions. Tourism management, 17(3), 175-182.

Oppermann, M., \& Chon, K. S. (1997). Convention participation decision-making process. Annals of Tourism Research, 24(1), 178-191.

Oral, J., \& Whitfield, J. (2010). The North Cyprus conference sector: Establishing a competitive advantage. Tourism Analysis, 15(4), 411-424.

Petersen, D. C. (2005). The city as a destination: Measuring its attractiveness. Journal of Convention \& Event Tourism, 6(1/2), 145-157. 
Ramirez, D., Laing, J., \& Mair, J. (2013). Exploring intentions to attend a convention: A gender perspective. Event Management, 17(2), 165-178.

Rittichainuwat, B. N., Beck, J. A., \& Lalopa, J. (2001). Understanding motivations, inhibitors, and facilitators of association members in attending international conferences. Journal of Convention \& Exhibition Management, 3(3), 45-62.

Robinson, L. S., \& Callan, R. J. (2002). Professional U K conference organizers' perceptions of important selection and quality attributes of the meetings product. Journal of Convention \& Exhibition Management, 4(1), 1-17.

Robinson, L. S., \& Callan, R. J. (2005). U K conference delegates' cognizance of the importance of venue selection attributes. Journal of Convention \& Event Tourism, 7(1), 77-95.

Rogers, T. (1998). Conferences: A twenty-first century industry. Adison Wesley Longman.

Rogers, T. (2008). Conferences and conventions: A global industry. Routledge.

Severt, K., Fjelstul, J., \& Breiter, D. (2009). A comparison of motivators and inhibitors for association meeting attendance for three generational cohorts. Journal of Convention \& Event Tourism, 10(2), 105-119.

Shin, Y. (2009). Examining the link between visitors' motivations and convention destination image. Tourismos: An International Multidisciplinary Journal of Tourism, 4(2), $29-45$.

Sikošek, M., Bojnec, Š., Fabjan, D. \& Uran Maravić, M. (2014). Obseg dejavnosti in neposredni ekonomski učinki kongresnega turizma $v$ Sloveniji: primer Ljubljana. Javna agencija SPIRIT Slovenija.

Swarbrooke, J., \& Horner, S. (2001). Business travel and tourism. Butterworth-Heinemann.
Tanford, S., Montgomery, R., \& Nelson, K. B. (2012). Factors that influence attendance, satisfaction, and loyalty for conventions. Journal of Convention \& Event Tourism, 13(4), 290-318.

The Global Association of the Exhibition Industry. (2016). Global exhibition barometer: A UFI report based on the results of a survey conducted in december 2015. http:// www.ufi.org/wp-content/uploads/2016/o1/UFI-Global _Exhibition_Barometer_report16b.pdf

United Nations World Tourism Organization. (2006). Measuring the economic importance of the meetings industry - Developing a tourism satellite account extension.

Upchurch, R. S., Jeong, G. H., Clements, C., \& Jung, I. (2000). Meeting planners' perceptions of site selection characteristics: The case of Seoul, Korea. Journal of Convention \& Exhibition Management, 2(1), 15-35.

Var, T., Cesario, F., \& Mauser, G. (1985). Convention tourism modelling. Tourism Management, 6(3), 194-204.

Weber, K., \& Chon, K. S. (2002). Convention tourism: International research and industry perspectives. The Haworth Press.

Whitfield, J., \& Webber, D. J. (2011). Which exhibition attributes create repeat visitation? International Journal of Hospitality Management, 30(2), 439-447.

Whitfield, J., Dioko, L. D. A., Webber, D., \& Zhang, L. (2014). Attracting convention and exhibition attendance to complex MICE venues: Emerging data from Macao. International Journal of Tourism Research, 16(2), 169-179.

Yoo, J. J. E., \& Chon, K. (2008). Factors affecting convention participation decision-making: Developing a measurement scale. Journal of Travel Research, 47(1), 113-122.

Zhang, H. Q., Leung, V., \& Qu, H. (2007). A refined model of factors affecting convention participation decisionmaking. Tourism Management, 28(4), 1123-1127. 